\title{
An Environment for Distributed Group Decision Making Using the Analytic Hierarchy Process'
}

\author{
Lauro Lage-Filho ${ }^{2}$
}

\begin{abstract}
This paper describes an environment for distributed group decision making built around the Analytic Hierarchy Process (AHP) and employing off-the-shelf software tools. This environment has been successfully applied for supporting multimillion dollar decisions in real-world situations at a large international organization. The following sections present the main components of the Distributed Group Decision Support (DGDS) environment, an illustrative case of its application, and the resuits of a comparison between the DGDS environment and a conventional, structured, face-to-face approach for group decision making.
\end{abstract}

\section{INTRODUCTION}

Future business organizations will likely have fewer layers of management. They will be information-based organizations resembling more a hospital, university, or symphony orchestra than present organizations (Drucker 1988). The pace of change is being accelerated by information technology (IT). Some modern organizations are already composed, at their operational level, of specialists who frequently combine their knowledge by acting as teams. Communications networks, one element of IT, have been enabling these teams to assemble and work together despite separation in distance and time and the location of organizational memory (Scott Morton 1991, 12). We can expect that the new organizational structures, with fewer managers in headquarters and specialists scattered in different places, will often rely on shared decision making. This will increase the need for Group Decision Support Systems (GDSS) and, in particular, for Distributed GDSS (DGDSS).

The Analytic Hierarchy Process (AHP), developed by Thomas Saaty at the Wharton School of Business, has been frequently applied to solve complex decision problems (Saaty 1990a). Moreover, after extensive use by its developer and other researchers as an aid for decision making, the AHP is now being advocated as an effective tool for the group decision making process (Diao and Zhou 1991; Dyer and Forman 1992; Liu 1991; Mitchell and Wasil 1989; Saaty 1989).

According to Herbert Simon's classical view, the decision making process can be divided into three phases: Intelligence (identify the central decision problem), Design (develop alternatives and establish criteria), and Choice (evaluate alternatives) (Simon 1960, 1). Usually, the AHP is

$1 \quad$ This paper is based on the author's doctoral dissertation defended on May 1994 at The George

Washington University. The doctoral research was supported by the Brazilian Government (CNPq and MARA).

: $\quad$ INTERNET: ax669c@gwuvm.gwu.edu 
viewed as a tool for the Choice phase, but it can be beneficial for the whole process. Several other tools, including database management systems, spreadsheets, and expert systems, can (and should) also be applied in the choice phase as well as in the other phases (Dyer and Forman 1991, 17; Turban 1993, 29).

To amplify the benefits of using AHP in the group decision making process, a computer-based environment has been developed in which the required tools are made available to the users as needed to support group decision making on a distributed basis. Ideally, the user will be guided in this environment to make proper use of the AHP and supporting tools without perceiving them individually, and will be able to participate in all phases of group decision making from his/her own workstation at his/her convenience. Such an environment will provide the following benefits to an organization:

a) better utilization of its human resources and knowledge to improve decision making;

b) a basis for research and analysis (organizational learning) to improve the decision making process itself, through the preservation of the details of each decision (organizational memory);

c) increased productivity of valuable decision makers and specialists by reducing the requirements for often difficult to coordinate personal meetings.

\section{Importance of this Work}

There are just a few computerized environments for supporting group decision making. Usually, they require the implementation of specially equipped rooms, are based on proprietary technology and tools, require trained facilitators, and are expensive (Roth et. al. 1993). Even fewer systems target specifically the distributed group decision making situation, i.e., fewer systems enable decision makers to participate in the decision making process from the place and at the time of their choice (Morrison and Cheng 1992, 1.03). None of the systems are based on off-the-shelf software, as is the one described here.

\section{COMPONENTS OF THE DGDS ENVIRONMENT}

The main components of the Distributed Group Decision Support (DGDS) environment ${ }^{3}$ are: (1) the Methodology for the decision making process that provides overall orientation to the decision makers; (2) the computer program Team Expert Choice that helps to structure and solve decision problems; (3) the computer program Lotus Notes that supports the implementation of a computer conference and enables decision makers to participate in the decision process at the time and location of their convenience; and (4) network and communications software connecting a server $^{4}$ to decision makers' personal computers located in their offices, homes, or on the road.

3 Hereafter in the text the expressions: management tool, distributed group decision support environment, and DGDS environment will be used interchangeably and will refer to the management tool object of this paper.

4 A server is usually a microcomputer dedicated to providing services enabiing a group of users to create and explore shared computational resources. 


\section{Methodology}

The methodology proposed in this work (see Table I) is based on Herbert Simon's model for the decision making process and has been adapted from "An Analytic Approach to Marketing Decisions" (Dyer and Forman 1991, 17). The existence of a decision problem (or opportunity) is assumed, as well as the fact that the group will generate a representation of the problem according with the AHP axioms (Harker 1989, 14).

TABLE I

Methodology

\section{Intelligence Phase}

- Discuss a preliminary problem statement in order to:

- obtain an enriched and consensual view of the problem.

Design Phase

Discuss an initial list of alternatives in order to:

- obtain a revised list of alternatives;

- obtain an initial set of objectives/criteria.

Discuss an initial set of objectives/criteria in order to:

- obtain a revised set of objectives/criteria.

Choice Phase

Structure one or more AHP/Expert Choice models in order to:

- obtain common (group) Expert Choice model(s).

Derive individual judgments (weights) and synthesize the common

Expert Choice model(s).

Incorporate the geometric mean of the individual weights into the common Expert Choice model(s) and synthesize the model(s).

Discuss and approve the final results and analyses.

Document the decision for justification and control. 
Description of the Methodology

\section{Intelligence Phase}

In this phase the group will discuss and approve a description of the decision problem. It is important to give the group the opportunity to understand the problem fully, because, among other important reasons, "it is not unusual that decision makers define and solve a wrong problem" (Shakun 1992). In that attempt, the group can reframe the problem or even define a new one, accepted as the real one or recognized to be more important than the original. This phase can be totally conducted through the computer conference.

\section{Design Phase}

Here the group will define its objectives and alternatives. It is a highly iterative process, since the list of alternatives likely will change and will be affected by the defined set of objectives. Some problems have a list of alternatives defined a priori, while other problems do not and will benefit from the definition of objectives before any alternative is even considered (Dyer and Forman 1991, 25; Keeney 1992). This phase too can be totally conducted through a computer conference.

\section{Choice Phase}

The starting point in this phase is to build a common representation of the problem to permit the group to express its preference for one (or one set) of the alternatives. One of the strengths of the AHP is to provide a clear, organized, and logical view of the decision problem. Usually, a problem can be represented in several ways; therefore, an opportunity is present here for the group to exert creativity (Saaty 1990b, 9). More experienced members can offer suggestions of modeis; the ensuing group discussion regarding the proposed models should lead to an improved and well understood group model.

The group model will have to be detailed, with each node being fully defined. This process often implies reviewing the problem statement, objectives, alternatives, and/or model structure. When the model is finally approved, it is a product of the group's work and is normally well accepted by the group members.

After the model is approved by the group, members will use it to make individual judgments about their preference for the alternatives and the importance of objectives. There are several advantages in having the group members individually enter judgments into an AHP model. First of all, they will be forced to think thoroughly about all aspects of the problem (or, at least, of those aspects they have been designated to consider). They will also have an opportunity to do their analysis and, therefore, to contribute their knowledge at their most productive time and pace, and will be protected from disturbing behavior from other members, common in group settings (Turban 1993, 358). Furthermore, they will be able to use resources generally not available to them at meetings (e.g. their computers, applications, and files; access to external databases; access to colleagues and experts). This capability can be viewed as an extension of the concept of 
private work as presented by Mandviwalla et. al. $(1991,603)$. Finally, they will be fully prepared to discuss their and other members' evaluations.

Once all the individual evaluations have been completed, the models should be combined. The combination of the individual modeis through the geometric means ${ }^{5}$ of their weights creates a convenient starting point for the group discussion that will follow. The preferences for the alternatives reflected in the combined model should be analyzed by the group members and compared with those in their individual models. This should be done for each objective node immediately above the alternatives' level in the AHP models. Here, there are two interesting possibilities. First, it is possible that a large majority of the evaluators will establish their preference in the "same direction" (i.e., alternative $\mathrm{A}$ is preferable to alternative B to some degree). Commonly, in this case, the geometric mean results will be easily accepted by the group. Even if it is the case, it will be desirable to enable the dissidents to explain their reasons for different judgment. The discussion will, often, lead to deeper understanding of the subject and lead to a higher degree of consensus. Second, it is also possible that the evaluators will be divided into two (or three) groups according to their preference for an alternative. This will indicate either an incomplete, superficial, discussion of the subject in the computer conference (or face-to-face meeting) or the need to modify the model, possibly redefining the objective. Depending on the situation, the group should further discuss the subject and either obtain additional information, or modify the model, or both. In most of the circumstances, a reevaluation of that portion of the model will be recommended and the same process (individual evaluations, aggregation through geometric mean, and discussion) should be followed.

When all the evaluations have been discussed in the way mentioned above, results at higher levels of the model need to be studied. Such study should be supported by sensitivity analysis tools, and offers a convenient occasion for a face-to-face meeting. It represents a crucial stage of the decision making process, and the participants (group members) will be fully prepared, because of their previous discussions on the conference, to contribute in a productive way.

After a decision has been reached, it should be documented. The conference and the Expert Choice model provide rich material for that purpose. Normally the report will be submitted for higher level approval and should be clear and concise.

\section{Team Expert Choice}

Team Expert Choice is a new version of Expert Choice, developed specifically to support the group decision making process. Among its added features, the program, in contrast with the regular Expert Choice version, permits the representation of complex problems through wider horizontal levels ( 9 instead of 7 nodes). It also permits the generation of copies of models and its later aggregation through automatic calculation of the geometric means of the individual models' judgments. This is done in addition to offering aids to better visualize the individual judgments (table showing all judgments under each objective, histograms, geometric variance). Finally, Team Expert Choice presents extensive support for face-to-face meetings with brainstorming, model generation, and voting tools incorporated.

The geometric mean is the only averaging method to use with the AHP (Aczel and Saaty 1983). 


\section{Lotus Notes}

Lotus Notes is a computer package offering a powerful set of integrated tools, mainly devoted to supporting document management and group communications. Notes has adequate features to implement the computer conference required by the DGDS environment proposed in this work. Its basic unit is a document database, which is composed of documents and views. Documents can contain any combination of text, graphics, image, voice, and computer files, including spreadsheets and reports. Views show the information contained in the database according to user specifications (e.g., documents can be organized and retrieved by category, author, or date of creation).

Many other characteristics of Lotus Notes are important for the purposes of this work. Perhaps the most important is its user friendliness. Notes has graphical user interface with pull-down and hierarchical menus, icons for common functions, multiple windows, and context sensitive help. The program also offers adequate document preparation and retrieval. Convenient support is offered during the document edition process, including: creation of tables; use of colors and fonts; cut, copy, and paste functions; spell checker; etc. The retrieval of documents can be made directly in the views or through full-text search. Lotus Notes has built-in electronic mail capabilities. This is very convenient to support group communication, principally when the organization to which the group members belong doesn't have such a system in place. The program allows for full integration with Windows applications, principally: spreadsheets, presentation graphics, wordprocessors, and relational database management systems, and is compatible with a large number of computer and network platforms.

\section{REAL WORLD PROJECT}

This section presents one of the three real world projects used to evaluate the DGDS environment. The projects were developed in a large multibillion-dollar international financial organization, hereafter referred to as the Firm.

The Firm is a modern, sophisticated organization with about 1,500 employees. It has had in place, for the last five years, a computer network connecting personal computers from each employee's office and supporting access to internal and external databases and other computer programs (a wordprocessor, a spreadsheet, and a relational data base management system are available in each workstation). Using computers is part of the organizational culture and internal communication depends heavily on electronic mail. As a requirement, the Firm's professionals are college-educated and many of them have studied at the graduate level. As expected, this condition is even more prevalent among its managers.

The developed projects, named PROJECT1, PROJECT2, and PROJECT3 dealt, respectively, with:

1. the selection of the best solution for the automation of the investment activities of the Firm. Three alternatives were considered;

2. the selection of the best solution for the automation of the Firm's account reconciliation process. Five alternatives were considered;

3. the selection of the best solution for the implementation of an electronic image management system for the Firm. Two alternatives were considered. 
The Firm nominated Advisory Committees (AC) and Project Teams (PT), either formally (PROJECT1, PROJECT2) or informally (PROJECT3), to work on the projects. The ACs were usually composed of managerial level members. These members were in charge of particular organizational units which were either users of, or responsible for the internal support of, the solution to be implemented. The initial role of the AC was to provide guidance to the PT about project goals, the decision making process, and the schedule to be followed. Additionally, the ACs analyzed and approved the results obtained by the PTs and prepared recommendations to support the Firm's final decision. The PTs were composed of staff or external consultants working for the units represented in the ACs. Members of the PTs usually knew the details of the problem to be solved and were selected to establish the preference for the alternatives under criteria approved by the ACs.

Table II describes the Firm's personnel who were directly involved in the projects. All have applied, to some extent, the methodology for group decision making prescribed in this work. The table indicates their organizational level (senior manager, manager, or staff), number of years in the organization ( $<5$ years, $>5$ years, $>10$ years), educational level, nationality, the projects they participated in, and their membership on either the Advisory Committees or the Project Teams of the projects.

\section{Project2}

The Firm has been operating its bank accounting reconciliation function through a manual process requiring the work of seven officers for ten working days each month. The process is complex because of a large and increasing number of accounts (about 250), a majority of them in US, Canadian, Japanese, or European currencies.

The Firm's Accounting Division (ACC) proposed the automation of the bank reconciliation project with the following rationale:

The Accounting Division believes that the maximum level of efficiency in - the current bank reconciliation process has been achieved given the constraints of the accounting system and personnel; however, additional improvements must be made to the reconciliation process to increase productivity and free staff resources to be assigned to [other] accounting control work. The Accounting Division has concluded that the most cost effective approach to increase productivity is to implement an electronic bank reconciliation system. Electronic bank reconciliation has been utilized by financial institutions for several years. Discussions with users and vendors indicate that it can automate the matching of transactions and significantly improve research and processing of outstanding exception items.

Many benefits of this automation project were identified by the ACC. Among them were: (1) savings in staff time corresponding to more than $\$ 100,000$ per year; (2) ability to cope with the expected future increase of transactions without hiring additional staff; (3) faster resolution of outstanding problems; (4) daily account balancing for critical bank accounts; and (5) more effective managerial controls.

PROJECT2's Project Team made a pre-selection from a number of companies offering solutions toward the implementation of an automated reconciliation system. These companies 
responded to the Firm's Request for Proposal and offered a total of five alternatives: ALT1, ALT2, ALT3, ALT4, and ALT5.

TABLE II

Firm's Personnel

\begin{tabular}{||l|l|l|l|l|l||}
\hline \multicolumn{1}{|c|}{ LEVEL } & TIME (years) & EDUCATION & COUNTRY & \multicolumn{1}{|c|}{ PROJECT } & \multicolumn{1}{|c||}{ AC/PT } \\
\hline Sr Manager 1 & $>10$ & LL.D. & USA & Proj1 & AC \\
\hline Sr Manager 2 & $<5$ & M.B.A. & USA & Proj1, Proj2 & AC \\
\hline Sr Manager 3 & $>10$ & M.B.A. & Country 7 & Proj1, Proj2 & AC \\
\hline Sr Manager 4 & $>10$ & M.A. & Country 6 & Proj2 & AC \\
\hline Sr Manager 5 & $>10$ & Ph.D. & Country 6 & Proj1, Proj3 & AC \\
\hline Manager 1 & $>5$ & M.S. & Country 1 & Proj3 & PT \\
\hline Manager 2 & $>10$ & M.S. & Country 3 & Proj3 & PT \\
\hline Manager 3 & $>10$ & B.B.A. & Country 5 & Proj1 & AC \\
\hline Manager 4 & $>10$ & M.B.A. & Country 6 & Proj2 & AC \\
\hline Manager 5 & $>10$ & B.B.A. & Country 4 & Proj3 & PT \\
\hline Manager 6 & $<5$ & B.A. & Country 2 & Proj1, Proj2 & AC \\
\hline Manager 7 & $>5$ & M.S. & Country 2 & Proj1, Proj2 & AC \\
\hline Staff 1 & $<5$ & M.S. & USA & Proj1 & PT \\
\hline Staff 2 & $>10$ & M.B.A. & USA & Proj1 & PT \\
\hline Staff 3 & $>10$ & B.A. & USA & Proj3 & PT \\
\hline Staff 4 & $<5$ & B.B.A. & USA & Proj2 & PT \\
\hline Staff 5 & $<5$ & B.B.A. & USA & Proj2 & PT \\
\hline Staff 6 & $<5$ & B.B.A. & USA & Proj1 & AC \\
\hline Staff 7 & $<5$ & M.S. & Country 8 & Proj2 & PT \\
\hline Staff 8 & $<5$ & M.B.A. & Country 2 & Proj1 & PT \\
\hline Staff 9 & $>10$ & B.A. & USA & Proj2 & PT \\
\hline Staff 10 & $>10$ & & Country 7 & Proj3 & PT \\
\hline
\end{tabular}


Description of the problem

The item "Problem Statement" in PROJECT2's computer conference reads:

PROJECT2's Project Team will evaluate and select an account reconciliation package to automate the reconciliation process conducted by the Accounting Section. The system will match bank statements transactions received via SWIFT or manually entered from printed statements to cash transactions recorded in the General Ledger, helping to identify discrepancies and assist in the subsequent investigations.

The system to be selected should also be able to handle other types of reconciliation but the initial scope of the project will be limited to the General Ledger bank statement reconciliation.

\section{Schedule}

The activities related to PROJECT2 were performed according to the following schedule:

10/14 Discuss AHP and methodology with the Project Team

10/15 Implement computer conference

10/18-10/27 Attend vendors' demonstrations of the alternatives

10/19-11/04 Clarify Problem Statement and Objective

Discuss alternatives' pros and cons

10/28-11/05 Structure AHP model

11/08 Approve AHP model (PT and AC)

Establish relative importance of objectives (AC members, in groups)

Establish preference for the alternatives (PT members, individually)

Consolidate evaluations (geometric means)

$11 / 12 \quad$ Discuss and approve results (PT)

Discuss results and present recommendation to the $\mathrm{AC}$

\section{The AHP Model}

The AHP model for PROJECT2 was developed by members of the PT and the AC. The final version was discussed and approved by its developers in a meeting, and individually with members of the AC who did not participate in the model's development (Sr. Manager 2, Sr. Manager 3, Sr. Manager 4, and Manager 4). The model and its results appear, respectively, on Figures 1 and 2. 


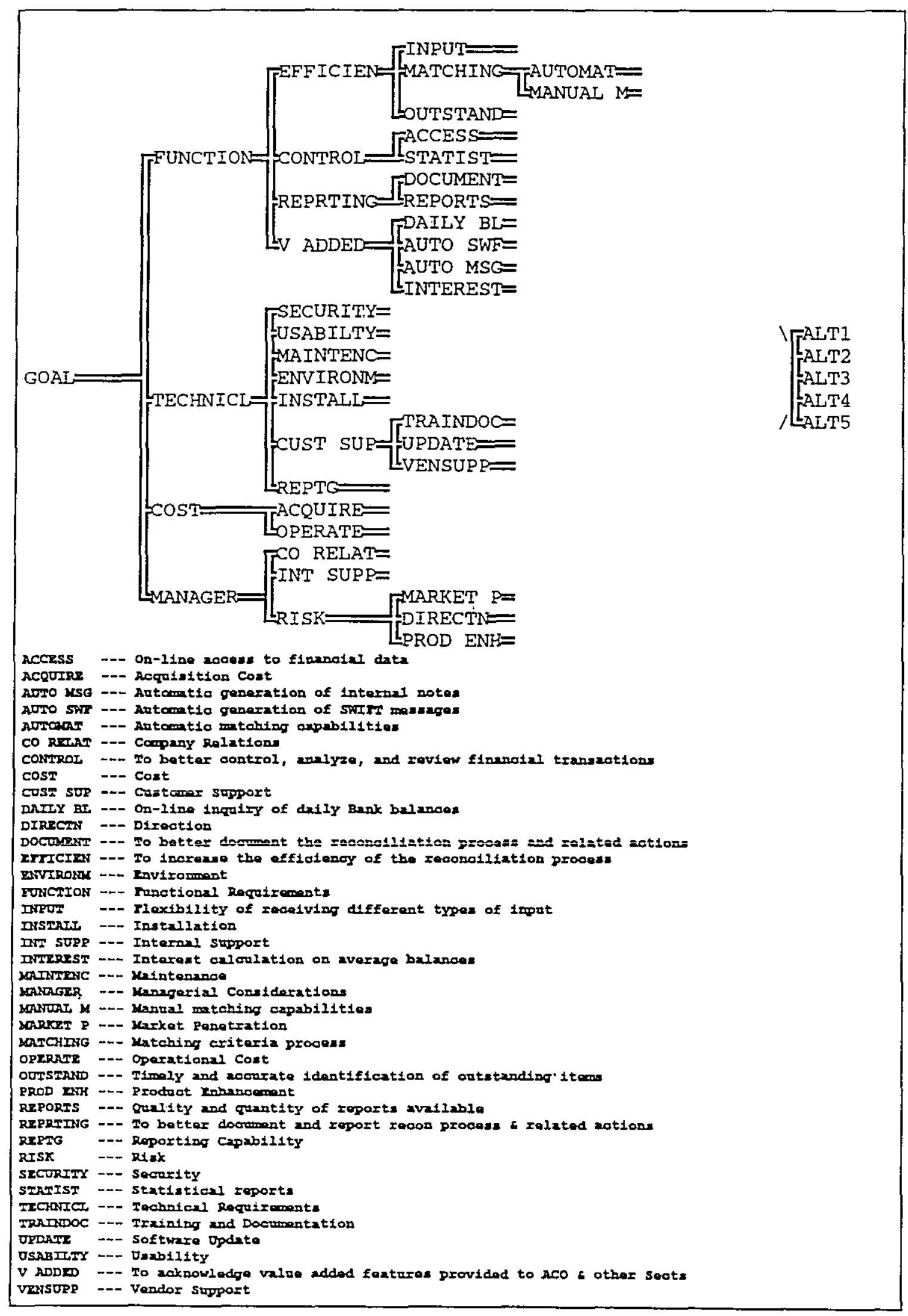

Fig. 1. AHP model for selecting the best solution to PROJECT2. 


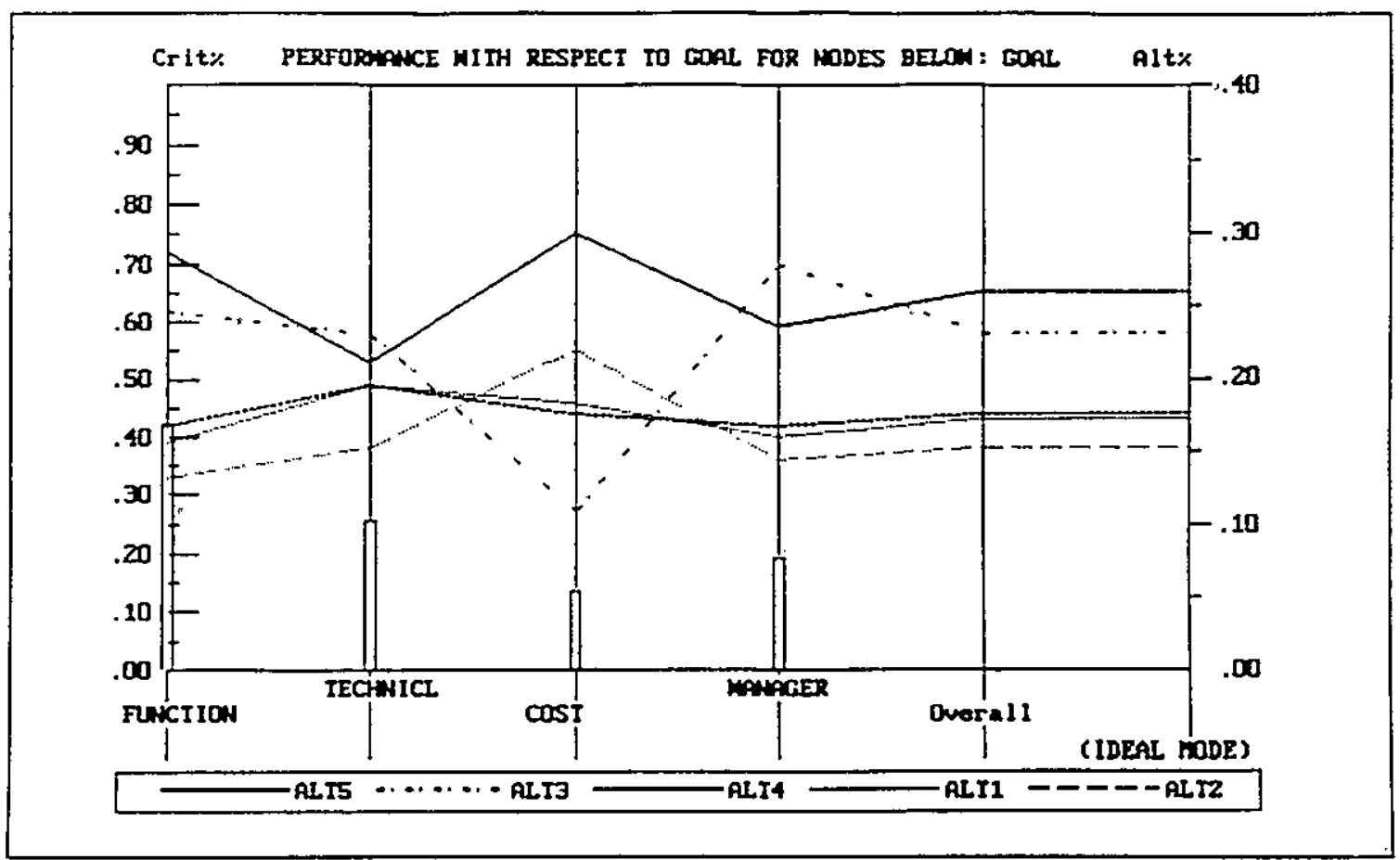

Fig. 2. Results of the AHP model for selecting the best solution to PROJECT2.

\section{Description of the PROJECT2 AHP model ${ }^{6}$}

The model consists of multiple evaluation levels, each consisting of multiple related evaluation criteria. The first level of the model is labeled the overall goal. The goal of the model is to select the best solution to PROJECT2 -- in other words, to recommend the package which would best meet the current Firm needs for the Bank reconciliation functionality performed by the ACC Section.

The second and subsequent (except the final) levels of the model define the sub-objectives or criteria to be used to judge the alternatives. These sub-objectives include functional requirements, technical requirements, cost, and managerial considerations:

Functional requirements cover the user's business needs, inciuding specific requirements in Matching Efficiency, Control and Reporting. Additionally, functional requirements considers "value added" features of the alternatives, such as automation of internal and external message creation, availability of Daily Balance reports, and Interest Calculation.

Technical requirements address important system features, such as security, usability, maintainability, computing environment, installation process, customer support, and reporting capabilities. The majority of these sub-objectives are further broken down to enable a complete and detailed analysis. 
Cost considerations encompass acquisition and operational costs. Acquisition cost is the cost of hardware and software required to install the software package. Operational cost is the cost to operate and support the system over a five year period.

Managerial considerations focus on company relations, internal support and risk appraisal. The company relations sub-objective is further subdivided into the flexibility of the company and its business orientation. The risk appraisal sub-objective is further broken down into market penetration, direction, and product enhancements.

The final level of the model contains the alternatives to be evaluated as solutions to PROJECT2. These alternatives are the software packages: ALT1, ALT2, ALT3, ALT4, and ALT5.

Analysis of the Process

\section{Methodology Presentation}

The overall methodology, including concepts of the AHP, was presented to members of the AC and PT in a four-hour, "hands-on" seminar. The presentation covered important aspects learned in PROJECT1, mainly related to the computer conference. Some of these aspects focused on the advantages of: participating frequently; using a meaningful subject line in each message; and keeping the messages short. Other aspects covered approaches for developing the AHP/EC model and for evaluating the alternatives. As a final activity in the seminar, the participants were asked to chose a personal decision problem to be represented and solved using the proposed methodology. The problem chosen dealt with buying a new house among four alternatives and was suggested by a group member who was actually involved in that type of acquisition. The exercise was very realistic and positively motivated the participants.

\section{Model Development}

Since the beginning of PROJECT2, a computer conference with the structure prescribed in this approach was active. The initial discussion had messages dealing with the objectives, the problem definition, and the schedule of activities.

The first two weeks were dedicated to a total of five half-day demonstrations of the alternatives by their vendors. The $\mathrm{AC} / \mathrm{PT}$ members attending those sessions were instructed to enter messages into the conference commenting upon the pros and cons of the demonstrated alternatives. They should enter their comment as soon as possible, preferably the same day of the session. A researcher's message in the conference gave them another instruction: "First, enter your comments; then, read others' contributions ...". The purpose here was to capture more of the participants' first impressions, and after that, give them an opportunity to be influenced by other members' opinions. The structuring of the AHP model started immediately after the end of the demonstration period. There were four two-hour face-to-face meetings for that purpose, including the one for the formal approval of the model. The computer conference continued highly active at that period and some messages dealt directly with the model's development. As a 
consequence of a suggestion presented in a message from Manager 7, who participated in the first project, PROJECT2's model was based on PROJECT1's model. ${ }^{7}$ The sub-objectives related to Functional Requirements, naturally, were particular to PROJECT2 and totally different from those of PROJECT1. The structures of PROJECT2's model under Technical Requirements, Cost, and Managerial Considerations simplified and redefined their equivalents in PROJECT1 and were kept very similar.

\section{Determination of the Importance of the Qbjectives}

The determination of the relative importance of the first level objectives (Functional Requirements, Technical Requirements, Cost, and Managerial Considerations) and of the sub-objectives related to Cost and Managerial Considerations) had been made by members of the Advisory Committee. These member were grouped accordingly to the division they represented:

- Cashier's Division, CSH

(Sr. Manager 4, Manager 4)

- Accounting Division, ACC

(Sr. Manager 2, Manager 6)

- Financial MIS Division, SUP

(Sr. Manager 3, Manager 7).

Members of each group worked together and used the Expert Choice program to derive the priorities of the objectives/sub-objectives. The geometric means of these priorities were calculated to represent the position of the AC. The relative importance of the sub-objectives under Functional Requirements was established by the $\mathrm{ACC}$ group and that of the sub-objectives under Technical Requirements was established by the SUP group. The final priorities of the combined model were not calculated until the preference for the alternatives had been established. This was done to avoid influencing the evaluators.

\section{Determination of the Preference for the Alternatives}

When considering the lowest level sub-objectives, the determination of the preference for the alternatives was made by AC and PT members grouped according to their area of expertise:

- Functional Requirements (Manager 6, Staff 5)

7
Author: "Manager $7 /$ The Firm"
Date Composed: $10 / 28 / 93$ 12:02 PM

Subject: $\quad$ Development of EC model

I suggest that we use the Managerial Considerations sub-tree of the PROJECT1 EC model for the PROJECT2 as well. I think it is directly applicable. The whole first level of PROJECT1/EC model could be used.

The TECHNICAL sub-tree could also be used with minor adjustments. 
- Technical Requirements

(Manager 7, Staff 7)

- Cost

(Manager 6, Manager 7)

- Managerial Considerations

(Manager 6, Manager 7).

The comparisons of the alternatives when considering Functional Requirements' and Technical Requirements' sub-objectives were made in two steps. First, the evaluators worked individually and their models were combined through the geometric means. After that, they discussed the differences in their individual evaluation and, by consensus, adjusted some of the results of the combined model. When establishing the preference for the alternatives under the other two objectives of the AHP model (Cost and Managerial Considerations), the evaluators worked together.

Prior to the evaluation work, the group members reclassified the relevant messages about the alternatives' pros and cons under conference items with the name of the sub-objectives to be considered. Additionally, they entered new information which they judged to be relevant. Finally, they received (in a computer conference message) orientation to concentrate only on the sub-objective being considered; to read a printout of the discussion under the corresponding computer conference's item; and to have all pertinent documentation available, consulting it as needed. The conference had 47 items with 484 responses. A printout of the conference generated 146 single-spaced pages.

\section{Validation of the Results}

The Project Team had a two-hour-long meeting to discuss and validate the final results. They analyzed and accepted the priorities derived by the $\mathrm{AC}$ and discussed the results under each of the main objectives in the model. Major differences among individual judgments and the combined model were mentioned and justified, and sensitivity analysis tools were used to support the final decision by the group. They reached a consensus decision appointing the ALT5 as the preferable one.

At the same day, in another two-hour-long meeting, the Project Team recommended that solution to the Advisory Committee. After thoroughly discussing the results under each of the main objectives in the model and making extensive use of the sensitivity analysis graphs, the AC approved by consensus the recommended solution.

\section{COMPARISON OF DECISION MAKING APPROACHES}

The author distributed forms and models to the people involved in the projects on which to compare the DGDS environment which they had applied with either (1) the conventional face-to-face group decision making process they had used before ${ }^{8}$ (if they were first-time users of the DGDS) or (2) the DGDS environment as applied in PROJECTI and, at the same time, with

8 The usual approach in the Firm for similar decision situations is structured, with face-to-face meetings having a facilitator, often a contents leader, and a secretary to prepare the meeting's aide-memoire. Project Team and Advisory Commintee are constituted. The work of the Project Team is guided by orientation from the Advisory Committee. Additionally, the Project Team follow the criteria established on a Request for Proposal document previously submitted to those who offered solutions (or alternatives). 
the conventional face-to-face group decision making process they had used before (if they were second-time users of the DGDS environment). The results of that comparison are summarized below:

1) Highly qualified professionals, applying the complete DGDS environment (methodology and computer conference) perceived that management tool as preferable to the conventional, structured, face-to-face approach for group decision making involving important and complex, real-world, decision problems. (PROJECT 1 \& PROJECT 2).

2) Highly qualified professionals, applying an incomplete DGDS environment (without the computer conference) perceived that management tool as preferable to the conventional, structured, face-to-face approach for group decision making involving an important and complex, real-world, decision problem. (PROJECT 3). The degree of preference was significant but much less than in (1) above that included the computer conference.

3) Highly qualified professionals perceived the DGDS environment, after a second-time use, as even more preferable than at the first-use of that management tool. (PROJECTS 1 and 2, second-time use).

\section{REFERENCES}

Aczel, J. and T. L. Saaty. 1983. Procedures for Synthesizing Ratio Judgements. Journal of Mathematical Psychology 27, 93-102.

Diao, H., and W. Zhou. 1991. The AHP of Group Multiple Round Feedback Judgment. In Proceedings of The 2nd International Symposium on The Analytic Hierarchy Process in Pittsburgh, Pennsylvania, USA, 1991, by the Joseph M. Katz Graduate School of Business of the University of Pittsburgh. USA: University of Pittsburgh, 135-148.

Drucker, P. 1988. The Coming of the New Organization. Harvard Business Review (January-February) 45-53.

Dyer, R. F., and E. H. Forman. 1991. An Analytic Approach to Marketing Decisions. Englewood Cliffs, N.J.: Prentice-Hall.

Dyer, R. F., and E. H. Forman. 1992. Group decision support with the Analytic Hierarchy Process. Decision Support Systems (8) 99-124.

Harker, P. 1989. The Art and Science of Decision Making: The Analytic Hierarchy Process. In The Analytic Hierarchy Process: Applications and Studies, eds. Golden, B. L., E. A. Wasil, and P. T. Harker, 3-36. Heildelberg: Springer-Verlag.

Keeney, R. L. 1992. Value-Focused Thinking. Cambridge: Harvard University Press. 
Lage-Filho, L. 1994. A Group Decision Support Environment Facilitating Decision Making Distributed in Time and Space. D.Sc. dissertation, The George Washington University.

Liu, B. 1991. Group Judgments and Analytic Hierarchy Process. In Proceedings of The 2nd International Symposium on The Analytic Hierarchy Process in Pittsburgh, Pennsylvania. USA. 1991, by the Joseph M. Katz Graduate School of Business of the University of Pittsburgh. USA: University of Pittsburgh, 149-156.

Mandviwalla, M., P. Gray, L. Olfman, and J. Satzinger. 1991. The Claremont GDSS Support Environment. In Proceedings of the Twenty-Fourth Annual Hawaii International Conference on System Sciences, edited by Jay F. Nunamaker, Jr., Los Alamitos, CA:IEEE Computer Society Press, 600-607.

Mitchell, K. H., and E. A. Wasil. 1989. AHP in Practice: Applications and Observations from a Management Consulting Pespective. In The Analytic Hierarchy Process: Applications and Studies, eds. Golden, B. L., E. A. Wasil, and P. T. Harker, 192-212. Heildelberg: Springer-Verlag.

Morrison, J. and O. R. L. Cheng. 1992. Communication technologies and collaboration systems: common domains, problems and solutions. Information \& Management 23, 93-112.

Roth M. R., W. C. Wood, R. Hahm, and D. J. Power. 1993. Building Group Decision Support Rooms using "off-the-shelf" Computing Resources: Prospects and Issues. DATABASE (May) 21-31.

Saaty, T. L. 1989. Group Decision Making and the AHP. In The Analytic Hierarchy Process: Applications and Studies, eds. Golden, B. L., E. A. Wasil, and P. T. Harker, 59-67. Heildelberg: Springer-Verlag.

Saaty, T. L. 1990a. The Analytic Hierarchy Process, 2d ed. Pittsburgh: RWS Publications.

Saaty, T. L. 1990b. How to make a decision: The Analytic Hierarchy Process. European Journal of Operational Research 48, 9-26.

Shakun, M. F. 1992. Defining a Right Problem in Group Decision and Negotiation: Feeling and Evolutionary Generating Procedures. Group Decision and Negotiation 1, 27-40.

Simon, H. 1960. The New Science of Management Decision. New York: Harper \& Row.

Scott Morton, M. 1991. Introduction. Chap. in The Corporation of the 1990s, ed. M. Scott Morton. New York: Oxford.

Turban, E. Decision Suppert and Expert Systems: Management Support Systems, 3d ed. New York: MacMillan. 